\title{
Comparative evaluation of modified pulse width modulation schemes of Z-source inverter for various applications and demands
}

\author{
S. Thangaprakash ${ }^{1}$, A. Krishnan ${ }^{2}$ \\ ${ }^{I^{*}}$ Department of Electrical Engineering, Sri Shakthi Institute of Engineering and Technology, Coimbatore (TN), - 641 062, INDIA \\ ${ }^{2}$ Dean (Academic), K.S.R. College of Engineering, Tiruchengode (TN), - 637 215, INDIA \\ "Corresponding Author: e-mail:s_thangaprakash@rediffmail.com
}

\begin{abstract}
This paper presents a comparative evaluation of five different methods of modified pulse width modulation schemes to control the recently developed buck-boost type Z-source inverter. Since its inception, different control techniques have been proposed to insert the shoot-through periods in the traditional switching waveform of the power switching devices. Simple boost control, maximum boost control, constant boost control and modified space vector modulation based control methods have been presented by world wide researchers for various types of loads and applications. However, the detailed comparative evaluation has not been reported to select the suitable control method according to the application and demand. In this paper, for the common boost factor and modulation index, the output voltage, output current, output line harmonics profile of the inverters with different PWM schemes powered by the same dc power supply and three phase RL load were conducted. Comparison results are analyzed for two control variables (modulation index and boost factor) and are evidently reported. For each method, the boost factor, voltage gain, duty ratio and voltage stress across the switches are expressed and the relationships among them are analyzed. By comparing them, proper control method can be adapted according to the requirement of different applications and demands.
\end{abstract}

Keywords: Z-source inverter, buck-boost, pulse width modulation (PWM), modified space vector modulation (MSVM), shoot-through, voltage stress.

\section{Introduction}

The distribution of the shoot-through in the switching waveforms of the traditional pulse width modulation concept is the key factor to control the Z-source inverter shown in Figure 1. The dc-link voltage boost (diagonal capacitor voltage), controllable range of ac output voltage, voltage stress across the switching devices and harmonic profile of the output profile are purely based on the method of control algorithm adapted to insert the shoot-through. There are a number of control methods which have been presented so far to control Z-source inverter, that include the sinusoidal PWM and modified space vector modulation based PWM techniques. In this paper, five types of PWM control algorithms: simple boost control (SBC), maximum boost control (MBC), constant boost control (CBC), and traditional and modified space vector based pulse width modulation schemes (MSVM) are comparatively evaluated for different operating modes. The buck-boost operation of the inverter is based on the boost factor, which in turn based on the placement of the shoot-through time period in between the active states. The shoot-through period is carefully inserted before or after the active states by keeping the time period of the active states constant (Loh et al., 2007).

The simple boost control is proposed by Peng (2003); it uses two straight lines equal to or greater than the peak value of the three phase references to control the shoot-through duty ratio in a traditional sinusoidal PWM. Simple boost control is very simple and easy to implement and in this method, switching stress is high. Maximum boost control method is proposed by Peng et al. (2005a). Under a given modulation index and shoot-through duty ratio, a maximum boost in the dc link voltage than simple boost control is achievable to produce the maximum voltage gain. A detailed analysis for how the various conventional pulse width modulation strategies can be modified to switch a Z-source inverter either continuously or discontinuously, while retaining all the unique harmonic performance features is clearly discussed by Loh et al. (2005). Shen et al. (2006) proposed constant boost control, this 
method provides a maximum voltage gain at any given modulation index without producing any low-frequency ripple that is related to the output frequency. Thus the Z-source network requirement will be independent of the output frequency and determined only by the switching frequency. Modified space vector modulation is proposed by Tran et al. (2007). Maximum voltage boost in the dc-link with improved harmonic profile at the output of the inverter by turning the maximum time period of the traditional zero state into shoot-through state with modified voltage space vector is reported by Thangaprakash et al. (2010a). This control method allows the Z-source inverter to be operated in wide range of control with improved performance.

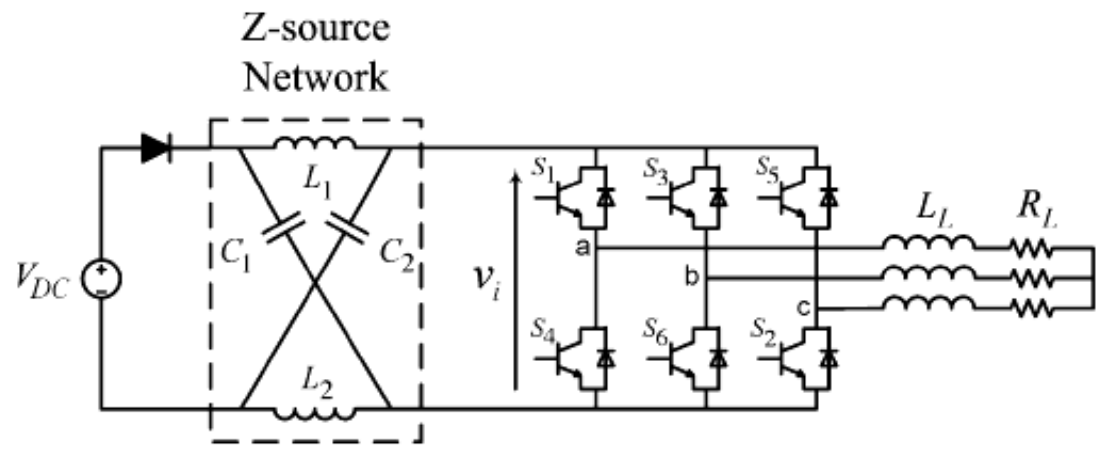

Figure 1 Structure of the three phase Z-source inverter

For the same boost factor, switching frequency and modulation index, the output voltage, output current, output line harmonics profile of the inverters powered by the same dc power supply and loaded by the same three phase RL load were conducted with different PWM techniques. In the next section, the aforementioned pulse width modulation schemes for Z-source inverters are investigated with their relevant expressions of key parameters that are followed by the simulation results of five major control methods, detailed comparative evaluation and analysis.

\section{Modulation schemes and parameters for evaluation}

Many PWM control methods have been developed and used for voltage source inverters (VSI). The voltage source inverter has six active states, when the dc voltage is immersed across the load, and two zero states when the load terminal are shorted through the lower or upper switches (results shoot-through). The Z-source inverter has an additional zero state, called shoot-through state. How to insert this shoot-through state becomes the key point of the PWM control methods for the Z-source inverter. In this section, five different control techniques for Z-source inverter are reviewed and the parameters for comparison are defined. In the next section, these control methods are analyzed and evaluated in many fonts like, boost factor (B), gain (G), voltage stress across the switches $\left(V_{s}\right)$ with respect to different shoot-through duty ratio $\left(D_{o}\right)$ and modulation index $\left(m_{a}\right)$. In SBC, MBC and CBC techniques, the three phase sinusoidal modulating signals with 120 degree phase shift are compared with the carrier triangular signal. When the magnitude of the modulating signal is greater than the carrier signal, the upper power switch in the respective phase leg is ON and the switch is OFF, when the modulating signal is less than the carrier signal. The complement signals are given to the lower switch of the phase leg. The shoot-through period is generated by comparing the same triangular wave with straight lines or envelopes of the modulating signal or sinusoidal signal depending upon the technique used and inserted in the switching waveform with the help of OR gate. In addition to the six active and two null states associated with a conventional VSI, the Z-source inverter has seven shoot-through states representing the short-circuiting of a phase-leg $\left(E_{I}\right)$, two phase-legs $\left(E_{2}\right)$ or all three phase-legs $\left(E_{3}\right)$. These shoot-through states again boost the dc link capacitor voltages and can partially supplement the null states within a fixed switching cycle without altering the normalized volt-sec average, since both states similarly short-circuit the inverter three-phase output terminals, producing zero voltage across the ac load (Woo et al., 2007). Shoot-through states can therefore be inserted to existing PWM state patterns of a conventional voltage source inverter to derive different modulation strategies for controlling a three-phase-leg z-source inverter (Thangaprakash et al., 2010b). Third harmonic injection method also implemented to eliminate third order harmonics from the ac output voltage and current profile.

\subsection{Simple boost control}

Simple boost control uses two straight lines to control the shoot-through states, as shown in Figure 2 (a). When the triangular carrier waveform is greater than the upper envelope, $V_{l}$, or lower than the bottom envelope, $V_{2}$, the circuit turns into shoot-through state. Otherwise it operates just as traditional carrier-based PWM. Figure 2 (a) shows the pulse generation of the three phase leg switches (S1, S3 and S5-positive group/upper switch and S2, S4 and S6-negative group/lower switch). This method is very uncomplicated; however, the resulting voltage stress across the device is relatively high because some traditional zero states are 
not utilized either partially or fully. For a complete switching period, $T_{S}$ is total switching period, $T_{0}$ is the zero state time period and $D_{0}$ is the shoot-through duty ratio $\left(D_{0}=\frac{T_{0}}{T_{S}}\right)$.

Then the boost factor (B) can be,

$$
B=\frac{1}{1-2 D_{0}}=\frac{1}{1-2 \frac{T_{0}}{T_{S}}}
$$

Voltage gain $(\mathrm{G})$ of the inverter can be written as,

$$
G=\frac{\hat{v}_{a c}}{v_{d c} / 2}=m_{a} * B=\frac{m_{a}}{1-2 D_{0}}
$$

Where $\hat{v}_{a c}$ is ac output voltage and $v_{d c}$ is input dc voltage.

Figure 2.(a) illustrates the simple control method that employs a straight line equal to or greater than the peak value of the three phase references to control shoot-through duty ratio in a traditional sinusoidal PWM for the modulation index $m_{a}=0.8$. The Zsource inverter maintains the six active states unchanged as the traditional carrier based PWM control. For this simple boost control, the obtainable shoot-through duty ratio decreases with the increase of $m_{a}$. The maximum shoot-through duty ratio of the simple boost control is limited to

$D_{0}=\left(1-m_{a}\right)$

thus reaching zero at a modulation index of one. In order to produce an output voltage that requires a high voltage gain, a small modulation index $\left(m_{a}\right)$ has to be used. However, small modulation indices result in greater voltage stress on the devices. When the modulation index is increased, the switching frequency of the inverter also increases and hence the switching losses.

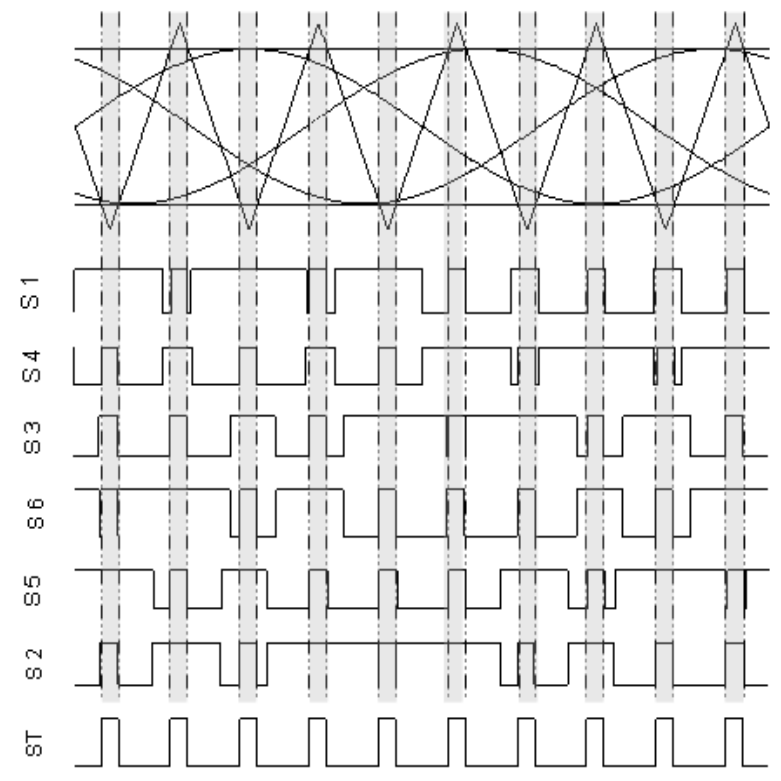

(a)

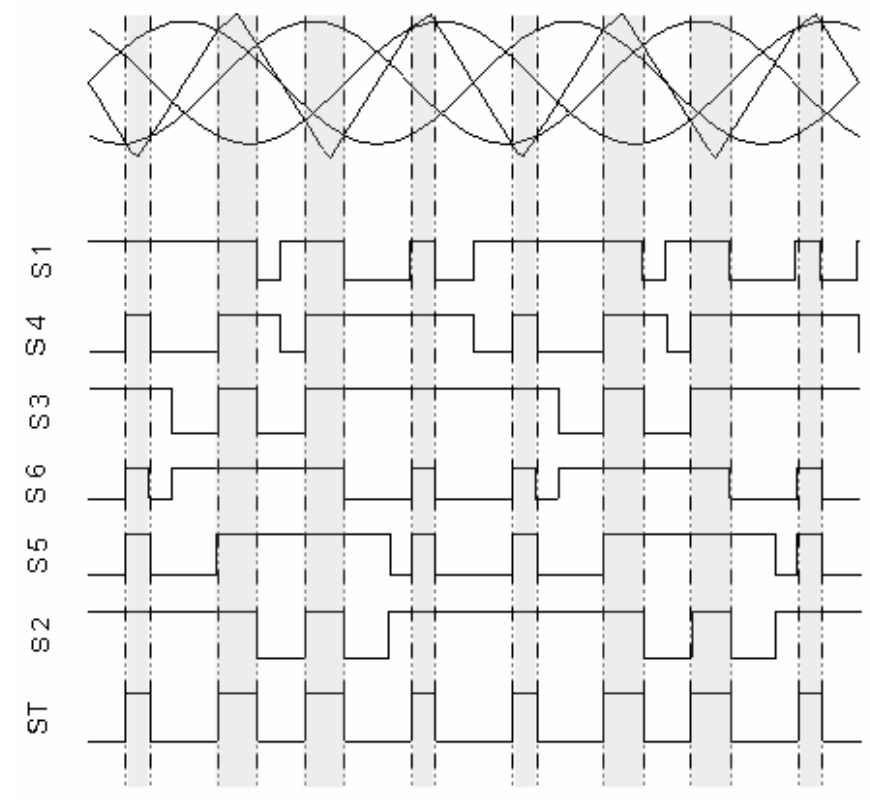

(b)

Figure 2 Modulation using (a) Simple boost control (b) Maximum boost control for $m_{a}=0.8$

The voltage gain of the inverter with simple boost control can be written by using equations (1) and (2) as

$G=m_{a} * B=\frac{\hat{v}_{a c}}{v_{d c} / 2}=\frac{m_{a}}{2 m_{a}-1}$

Then the modulation index $\left(m_{a}\right)$ can be related with the voltage gain $(G)$ of the inverter as.

$m_{a}=\frac{G}{2 G-1}$ 
The voltage stress across the power switches can be,

$V_{S}=B^{*} V_{0}=(2 G-1) V_{0}$

The voltage stress across the switches is quite high when simple boost control is used, this characteristic will restrict the obtainable voltage gain because of the limitation of device voltage rating (Shen et al., 2006).

\subsection{Maximum boost control}

Maximum boost control turns all traditional zero states into shoot-through state, as shown in Figure 2 (b). The voltage stress across the switching devices is greatly reduced by fully utilizing the zero states. Indeed, turning all zero states into shoot-through state can minimize the voltage stress; however, doing so also causes a shoot-through duty ratio varying in a line cycle, which causes inductor current ripple (Shen et al, 2008). This will require a high inductance for low-frequency or variable-frequency applications.

Maximum boost control method maintains the six active states unchanged and turns all zero states into shoot-through zero states. Thus maximum $T_{0}$ and $B$ are obtained for any given modulation index $m_{a}$ without distorting the output waveform. Reducing the voltage stress under a desired voltage gain now becomes important to the control of Z-source inverter. As analyzed in simple boost control method, the voltage gain is defined as $m_{a} * B$, and the voltage stress across the switches is $B^{*} V_{d c}$, therefore, to minimize the voltage stress for any given voltage gain, we have to minimize $B$ and maximize $m_{a}$, with the restriction of that their product is the desired value. On the other hand, we should maximize $B$ for any given modulation index to achieve the maximum voltage gain. Consequently, from the above discussion, we have to make the shoot-through duty ratio as large as possible.

As can be seen from Figure 2 (b), the circuit is in shoot through state when the triangular carrier wave is either greater than the maximum curve of the references $\left(V_{a}, V_{b}\right.$ and $\left.V_{c}\right)$ or smaller than the minimum of the references. The shoot-through duty cycle varies each cycle.

The shoot-through state repeats periodically in every $n / 3$ degrees. Assume that the switching frequency is much higher than the modulation frequency; the average shoot-through duty ratio over one switching cycle in the interval $\left(\frac{\pi}{6}, \frac{\pi}{2}\right)$ can be expressed as

$\frac{\hat{T}_{0}}{T}=\int_{\pi / 6}^{\pi / 2}\left(\frac{\left(2-m_{a} \sin \theta-m_{a} \sin (\theta-2 \pi / 3)\right)}{2}\right) d \theta$

$=\frac{2 \pi-3 \sqrt{3} \pi}{2 \pi}$

Maximum shoot-through duty ratio can be written as,

$$
\begin{aligned}
& B=\frac{1}{1-2 D_{0}}=\frac{1}{1-2 \frac{T_{0}}{T}} \\
& D_{0}=\frac{2 \pi-3 \sqrt{3} \pi}{2 \pi}
\end{aligned}
$$

The relationship of gain and modulation index,

$$
G=\frac{m_{a}}{1-2 D_{0}}=\frac{m_{a} \pi}{3 \sqrt{3} m_{a}-\pi}
$$

The relationship of modulation index and Gain,

$$
m_{a}=\frac{\pi G}{3 \sqrt{3} G-\pi}
$$

Then,

$$
B=\frac{3 \sqrt{3} G-\pi}{\pi}
$$

The voltage stress on the switch is,

$V_{S}=B^{*} V_{d c}=\frac{3 \sqrt{3} G-\pi}{\pi} V_{d c}=\frac{\pi}{3 \sqrt{3} G-\pi} V_{d c}$

Maximum boost control method introduces a low frequency current ripple associated with the output frequency in the inductor current and the capacitor voltage (Shen et al., 2006). Maximum boost control with third harmonic injection method is shown in Figure 3 (a). This method of control produces the output voltage and current with better harmonic profile. 


\subsection{Constant boost control}

In order to reduce the volume and cost, it is important always to keep the shoot-through duty ratio constant. At the same time, a greater voltage boost for any given modulation index is desired to reduce the voltage stress across the switches. Figure 3 (b) shows the generation of switching pulses by maximum constant boost control method, which achieves the maximum voltage gain while always keeping the shoot-through duty ratio constant.

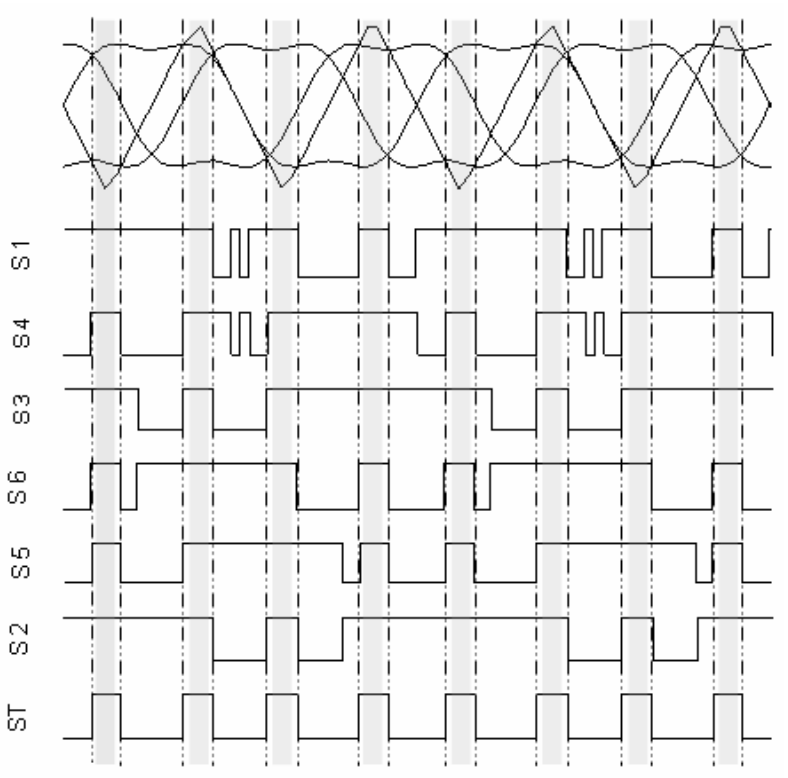

(a)

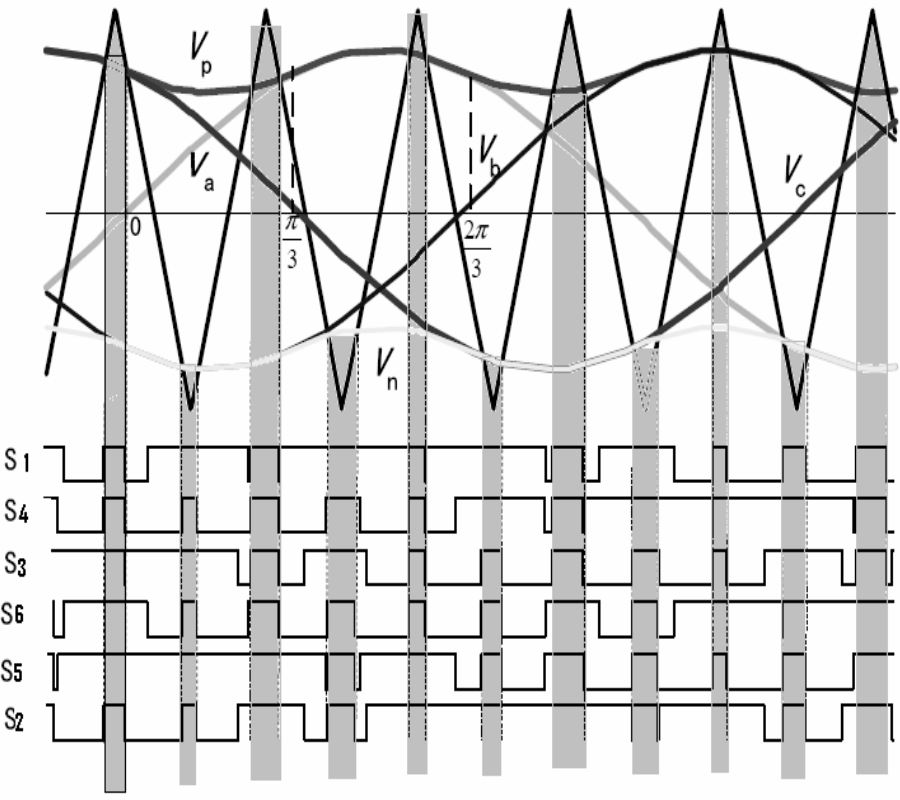

(b)

Figure 3 Modulation using (a) maximum boost control with third harmonic injection (b) constant boost control for $m_{a}=0.8$

There are five modulation curves in this control method: three reference signals, $V_{a}, V_{b}$, and $V_{c}$, and two shoot-through envelope signals, $V_{p}$ and $V_{n}$. When the carrier triangle wave is greater than the upper shoot-through envelope, $V_{p}$, or lower than the lower shoot-through envelope, $V_{n}$, the inverter is turned to a shoot-through zero state. In between, the inverter switches in the same way as in traditional carrier-based PWM control. The sketch map of maximum constant boost control is shown in Figure 3 (b). This method achieves maximum boost while keeping the shoot-through duty ratio always constant; thus it results in low line frequency current ripple through the inductors. With this method, the inverter can buck and boost the voltage from zero to any desired value smoothly within the limit of the device voltage.

The shoot-through duty ratio is;

$D_{0}=\frac{2-\sqrt{3} m_{a}}{2}=1-\frac{\sqrt{3} m_{a}}{2}$

Boost factor (B), can be found as,

$$
B=\frac{1}{1-2 \frac{T_{0}}{T}}=\frac{1}{\sqrt{3} m_{a}-1}
$$

Similarly, the voltage gain can be found as;

$$
\frac{\hat{v}_{i}}{V_{d c} / 2}=m_{a} * B=\frac{m_{a}}{\sqrt{3} m_{a}-1}
$$

The voltage gain approaches infinity when $m_{a}$ decreases to $\frac{1}{\sqrt{3}}$

Voltage gain is,

$$
G=m_{a} * B=\frac{m_{a}}{\sqrt{3} m_{a}-1}
$$

Then 
$m_{a}=\frac{G}{\sqrt{3} G-1}$

The voltage stress across the device can be;

$V_{S}=B * V_{d c}=(\sqrt{3} G-1) V_{d c}$

This method is very suitable for low-frequency applications, since it minimizes the Z-source network.

\subsection{Traditional SVM for Z-source inverter}

There are fifteen switching states of a three-phase-leg Z-source inverter. In addition to the six active and two null states associated with a conventional VSI, the Z-source inverter has seven shoot-through states representing the short-circuiting of a phase-leg $\left(E_{1}\right)$, two phase-legs $\left(E_{2}\right)$ or all three phase-legs $\left(E_{3}\right)$. These shoot-through states boost the dc link capacitor voltages and can partially supplement the null states within a fixed switching cycle without altering the normalized volt-sec average. The continuous centered SVM state sequence of a conventional three-phase-leg VSI, where three state transitions occur (e.g., null $(000) \rightarrow$ active $(100) \rightarrow$ active (110) $\rightarrow$ null (111) ) and the null states at the start and end of a switching cycle $T_{s}$ span equal time intervals to achieve optimal harmonic performance (Loh et al., 2005). With three-state transitions, three equal-interval (either $\frac{T_{0}}{T_{S}}$ or $\frac{T_{0}}{3 T_{S}}$ ) shoot-through states can be added immediately adjacent to the active states per switching cycle for modulating a Zsource inverter where $T_{0}$ is the shoot through time period in one switching cycle. The switching pattern is shown in Figure 4 (a).

The shoot-through states are symmetrically placed about the original switching instant. The modulating signal for the modified SVM strategy can be derived from the following equations,

$$
\begin{aligned}
& V_{\max (s p)}=V_{\max }+V_{o f f}+T \\
& V_{\max (s n)}=V_{\max }+V_{o f f}+\frac{T}{3} \\
& V_{\operatorname{mid}(s p)}=V_{\operatorname{mid}}+V_{o f f}+\frac{T}{3} \\
& V_{\operatorname{mid}(s n)}=V_{\operatorname{mid}}+V_{o f f}-\frac{T}{3} \\
& V_{\min (s p)}=V_{\min }+V_{o f f}-\frac{T}{3} \\
& V_{\min (s n)}=V_{\min }+V_{o f f}-T \\
& \{s p, s n\}=\{1,4\},\{3,6\},\{5,2\}
\end{aligned}
$$

Where $T=\frac{T_{0}}{T_{S}}$ shoot through duty ratio and $s p$ and $s n$ are switches connected in positive dc rail and negative dc rail.

The shoot-through duty ratio is;

$$
D_{0}=\frac{3}{4} * \frac{2 \pi-3 \sqrt{3} m_{a}}{2 \pi}
$$

Boost factor (B), can be found as,

$$
B=\frac{4 \pi}{9 \sqrt{3} m_{a}-2 \pi}
$$

Similarly, the voltage gain can be found as;

$$
G=\frac{\hat{v}_{i}}{V_{d c} / 2}=\frac{4 \pi m_{a}}{9 \sqrt{3} m_{a}-2 \pi}
$$

The voltage stress across the device can be;

$$
V_{S}=\frac{9 \sqrt{3} G-4 \pi}{2 \pi} V_{d c}
$$




\subsection{Modified SVM for Z-source inverter}

With three-state transitions, three equal-interval $\left(\frac{T_{0}}{3}\right)$ shoot-through states can be added immediately adjacent to the active states per switching cycle for modulating a Z-source inverter where $T_{0}$ is the shoot through time period in one switching cycle. Preferably, the shoot-through states should be inserted such that equal null intervals are again maintained at the start and end of the switching cycle to achieve the same optimal harmonic performance. The middle shoot-through state is symmetrically placed about the original switching instant. The active states $\{100\}$ and $\{110\}$ are left/right shifted accordingly by $\left(\frac{T_{0}}{3}\right)$ with their time intervals kept constant, and the remaining two shoot-through states are lastly inserted within the null intervals, immediately adjacent to the left of the first state transition and to the right of the second transition. This way of sequencing inverter states also ensures a single device switching at all transitions, and allows the use of only shoot-through states $E_{1}, E_{2}$, and $E_{3}$. The other shootthrough states cannot be used since they require the switching of at least two phase-legs at every transition. Modified space vector modulation allows the inverter to be operated in wide range of voltage control. DC-link voltage is boosted well than the traditional method and the output voltage of the Z-source inverter has better harmonic profile with wide controllability for the same shootthrough duty ratio, modulation index, input and load conditions (Thangaprakash et al., 2010a). The switching wave forms for six power transistors using modified space vector with proper placement of shoot through states in which both power switches in a leg are simultaneously turned on is shown in Figure 4 (b). The modulating signal for the modified SVM strategy can be derived from the following equations,

$$
\begin{aligned}
& V_{\max (s p)}=V_{\max }+V_{o f f}+T \\
& V_{\max (s n)}=V_{\max }+V_{o f f} \\
& V_{\operatorname{mid}(s p)}=V_{\operatorname{mid}}+V_{o f f} \\
& V_{\operatorname{mid}(s n)}=V_{\operatorname{mid}}+V_{o f f}-T \\
& V_{\min (s p)}=V_{\min }+V_{o f f}-T \\
& V_{\min (s n)}=V_{\min }+V_{o f f}-2 T \\
& \{s p, s n\}=\{1,4\},\{3,6\},\{5,2\}
\end{aligned}
$$

Where $T=\frac{T_{0}}{3}$ shoot through duty ratio.

In the case of traditional pulse width modulation method of Z-source inverters, all the switching functions are altered with $\frac{T_{0}}{3}$ either added with the active time or take out from them. But in modified space vector modulation, the active states of two switches remain unaltered neither added nor reduced by the shoot-through (Tran et al., 2007). Normally the shoot-through duty ratio is defined as follows,

$D_{0}=\min \left(\frac{T_{z}}{T_{S}}\right) ;$ for $\theta=0 \rightarrow 2 \pi$

Further $D_{0}$ could be related with the modulation index $m_{a}$ as,

$$
\begin{aligned}
& D_{0}=1-m_{a} \\
& B=\frac{1}{1-2 D_{0}}=\frac{\pi}{3 \sqrt{3} m_{a}-\pi}
\end{aligned}
$$

Similarly, the voltage gain can be found as;

$$
G=\frac{\hat{v}_{i}}{V_{d c} / 2}=\frac{\pi m_{a}}{3 \sqrt{3} m_{a}-\pi}
$$

The voltage stress across the device can be; 
$V_{S}=\frac{3 \sqrt{3} G-\pi}{\pi} V_{d c}$

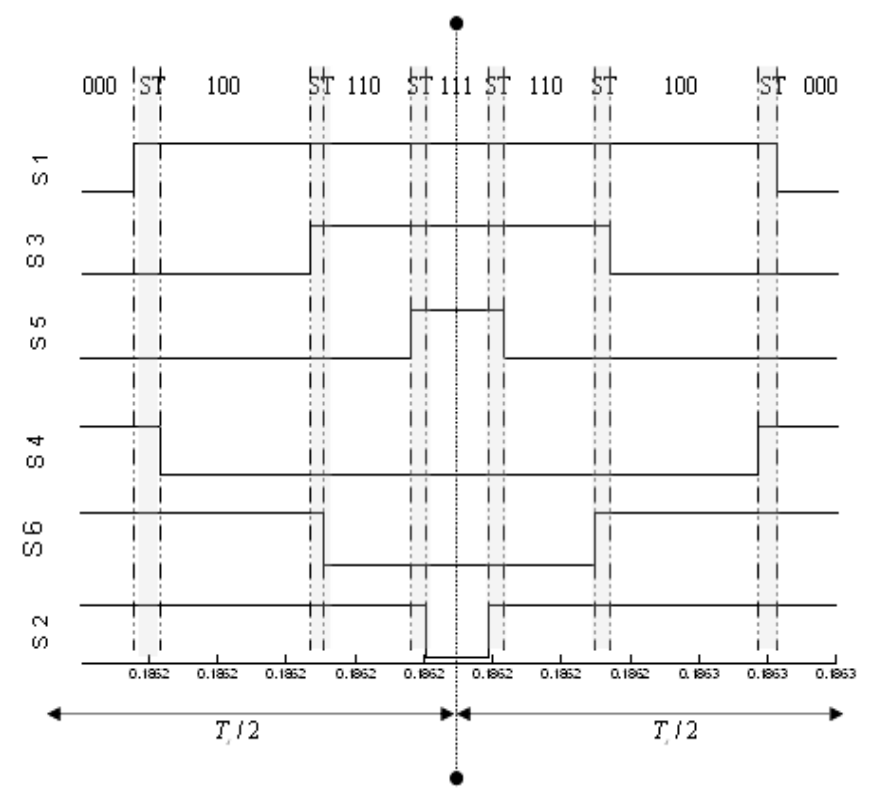

(a)

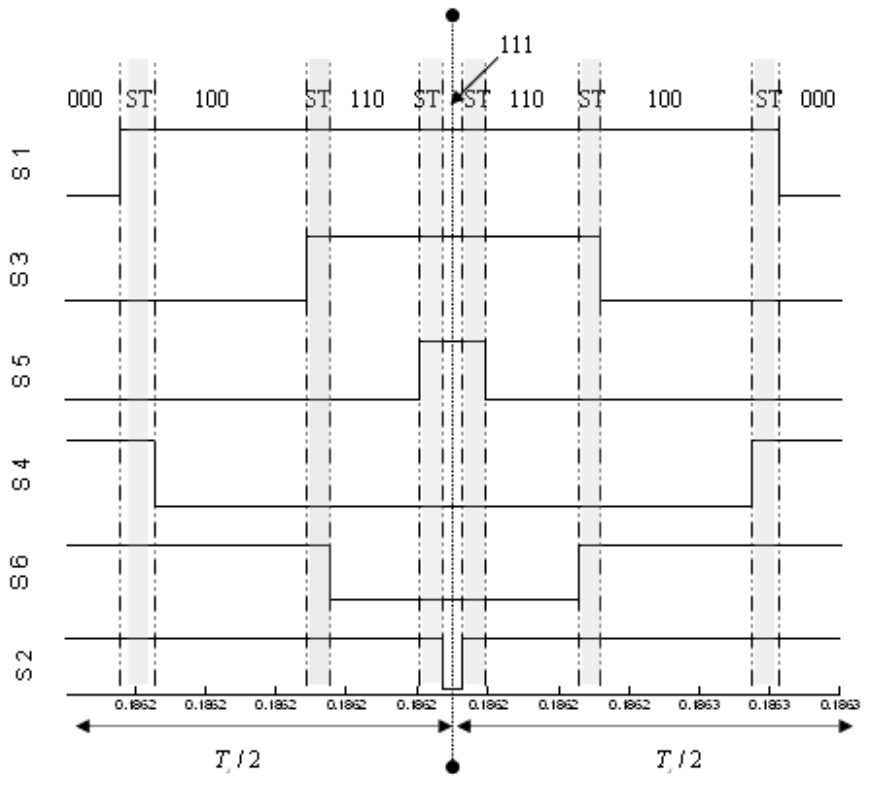

(b)

Figure 4 Modulation using (a) traditional SVM (b) modified SVM in sector-I

\section{Results and discussion}

A comprehensive comparison of the above control methods for Z-source inverter systems has been performed. The comparison results are analyzed for two control variables (modulation index and boost factor) and are shown in this section. For each method, the boost factor, voltage gain, duty ratio and voltage stress across the switches are expressed and the relationships among them are analyzed in detail. Figures 5-9 show the simulation results of the Z-source inverter having the following specification:

Z-source inductors, $L 1=L 2=L=160 \mu \mathrm{H}$,

Z-source capacitors, $C 1=C 2=C=1000 \mu F$,

Load resistance, $R_{L}=5$ ohms,

Load inductance, $L_{L}=2 \mathrm{mH}$,

Source voltage, $V_{d c}=250 \mathrm{~V}$,

Modulation index, $m_{a}=0.8$ and

Switching frequency, $f_{s}=5 \mathrm{kHz}$,

Shoot-through duty ratio, $D_{0}=0.3$ for $S B C, M B C$ and $C B C \& 0.2$ for traditional and modified SVM techniques.

The comparative graphs for different parameters are shown in Figures 10-11 and the harmonic profile comparison for four different cases: case I: Pure resistive load, case II: RL load, case III: Motor load, case IV: Motor load after a supply voltage sag (from $230 \mathrm{~V}$ to $170 \mathrm{~V}$ ) are depicted in Table 1.
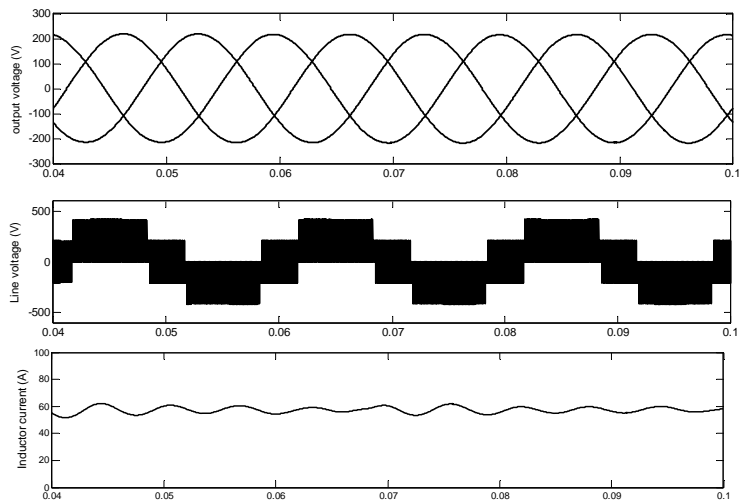
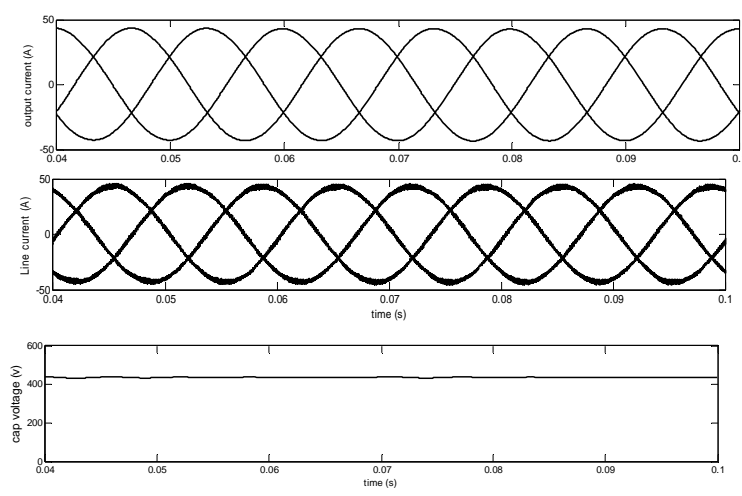

Figure 5 Simulation results of simple boost control 

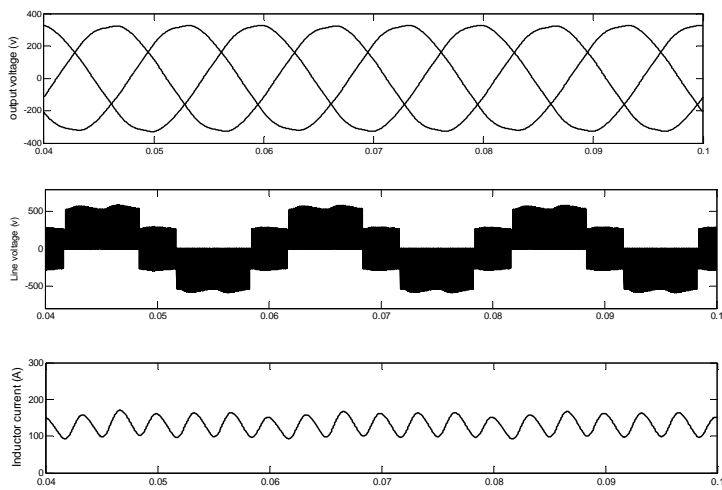
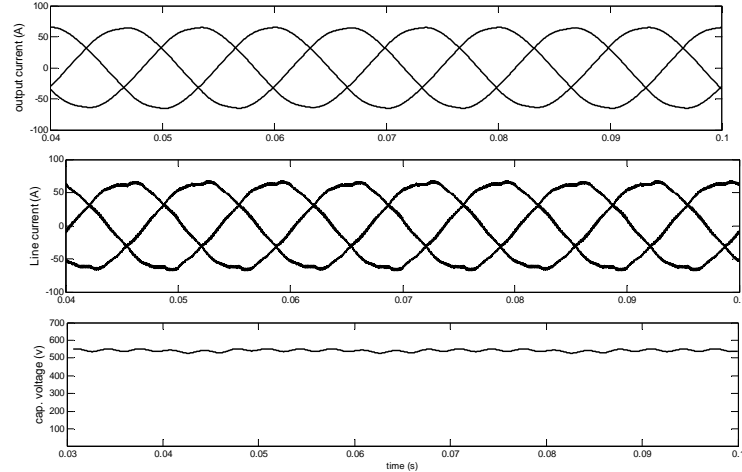

Figure 6 Simulation results of maximum boost control
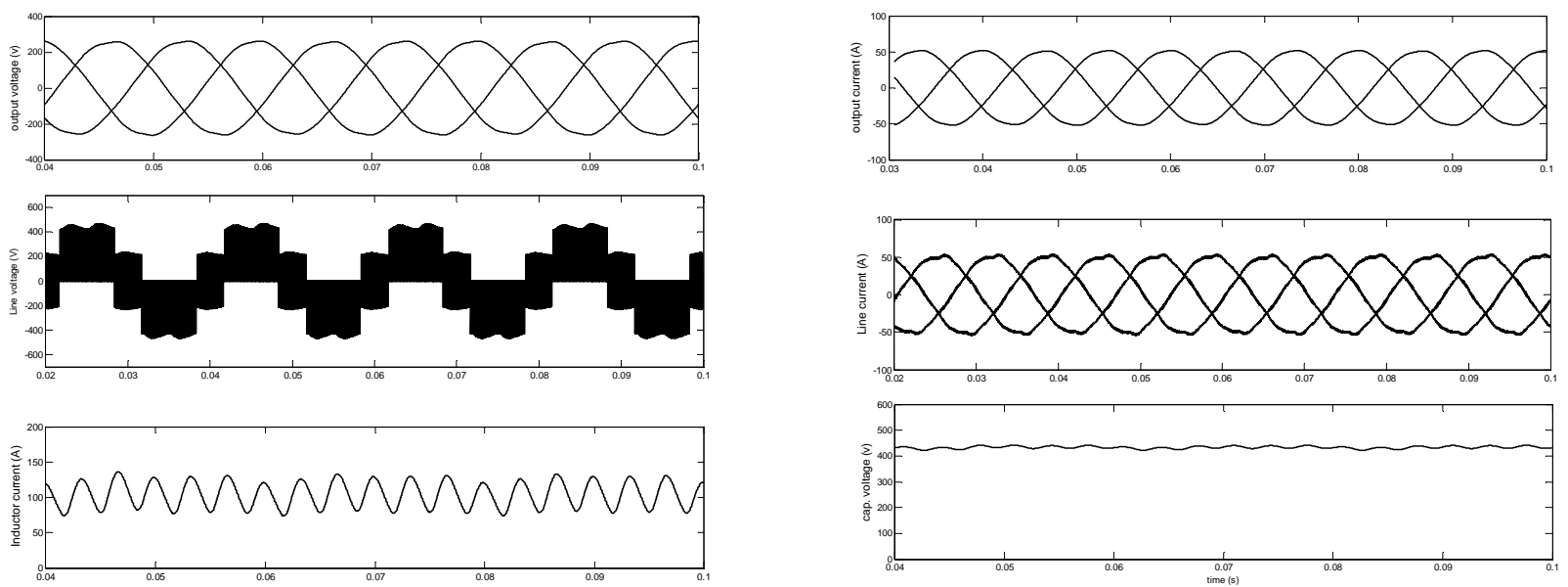

Figure 7 Simulation results of constant boost control
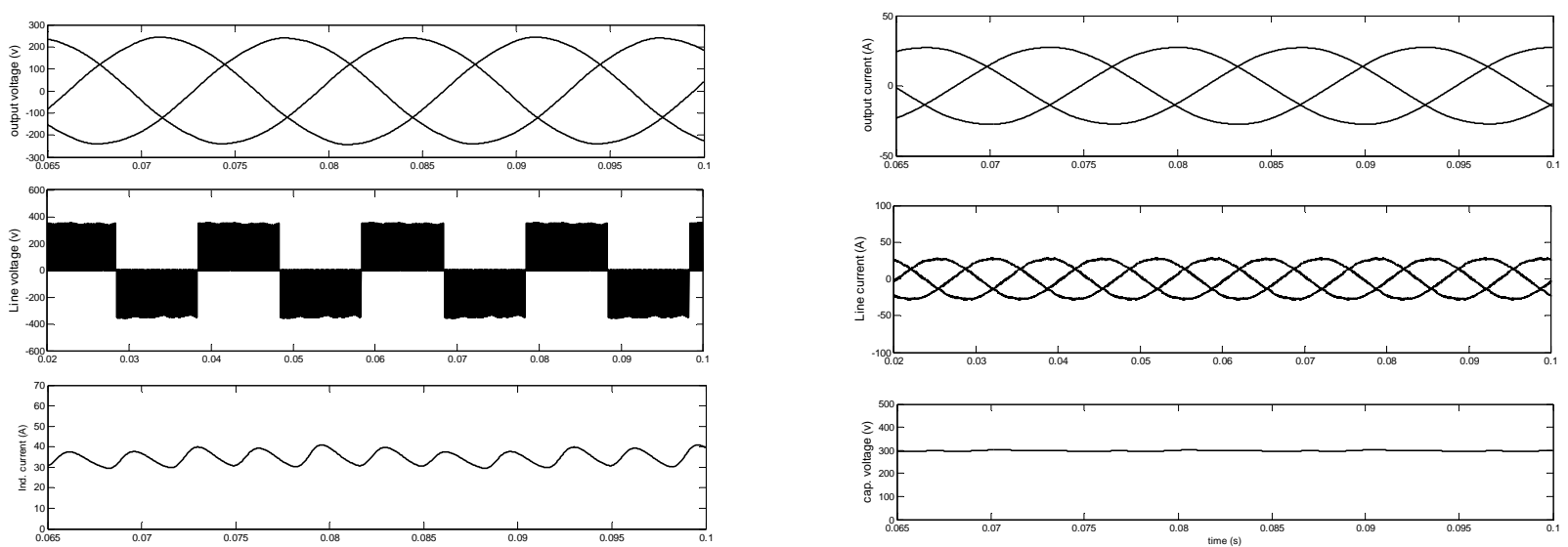

Figure 8 Simulation results of traditional SVM control 

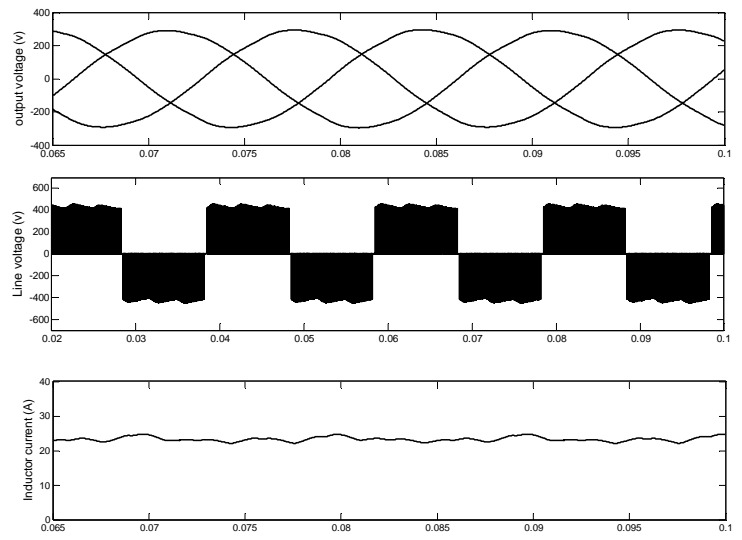
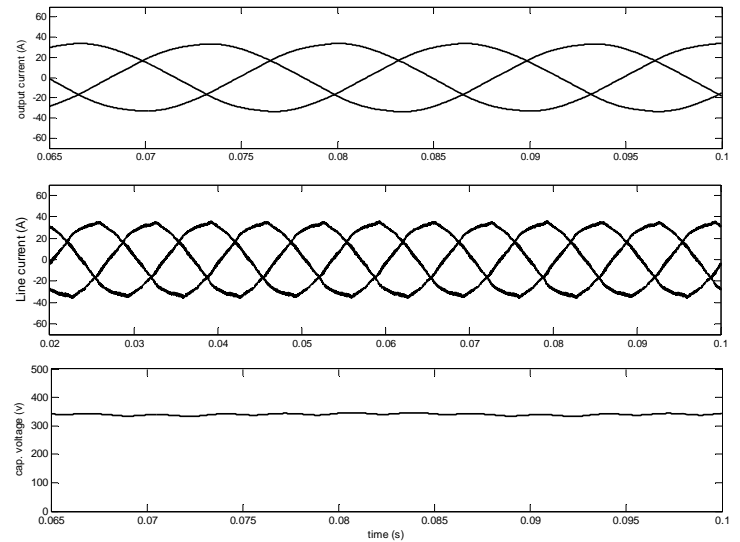

Figure 9 Simulation results of modified SVM control

The comparative evaluations of different methods are discussed in this section. The graph between voltage gain and modulation index has been depicted in Figure 10. Comparatively, modified SVM control technique provides better voltage gain among all the control techniques. Maximum boost control method maximizes the shoot through period without effecting the active states by turning all zero states into the shoot through zero state, thus maximum output voltage can be obtained for a given modulation index. Table 1 shows the harmonic profile of different control schemes for different operating conditions. It shows modified space vector modulation provides better harmonic profile in almost all cases.

Table 1 Comparison of the harmonic profile

\begin{tabular}{|c|c|c|c|c|}
\hline Method & \multicolumn{2}{|c|}{ Case I } & \multicolumn{2}{c|}{ Case II } \\
\hline & $T H D_{\nu} \%$ & $T H D_{i} \%$ & $T H D_{\nu} \%$ & $T H D_{i} \%$ \\
\hline SBC & 85 & 0.6 & 67 & 1.2 \\
\hline MBC & 66 & 3.13 & 46 & 3.2 \\
\hline CBC & 71 & 0.5 & 52 & 1.1 \\
\hline TSVM & 72 & 2.18 & 56 & 2.8 \\
\hline MSVM & 56 & 0.43 & 34 & 0.6 \\
\hline Method & \multicolumn{2}{|c|}{ Case III } & \multicolumn{2}{c|}{ Case IV } \\
\hline SBC & 76 & 1.4 & 74 & 3.5 \\
\hline MBC & 39 & 1.9 & 32 & 2.8 \\
\hline CBC & 45 & 0.6 & 39 & 1.2 \\
\hline TSVM & 48 & 2.1 & 36 & 1.4 \\
\hline MSVM & 29 & 0.8 & 31 & 2.1 \\
\hline
\end{tabular}

The voltage gain is identical to the maximum control method for the same modulation index. The curve of voltage gain versus modulation index is shown in Figure 10 (a), from which we can see that the possible operation region is extended with the increase of modulation index. The relationship of voltage gain versus voltage stress is shown in Figure 10 (b). From Figure 10 (a), the two control methods have identical voltage gain-modulation index relationship. Therefore they should share the same voltage stress for any given voltage gain except that the range of voltage gain is extended in the third harmonic injection method. Figure 10 (c) shows the relation between voltage stress $\left(V_{s}\right)$ and modulation index $\left(m_{a}\right)$ for different control methods. It is clear that, the voltage stress of the power switching devices is decreased when the modulation index is increased. The modified space vector modulation technique provides superior operation, when it is compared with all other control methods. Maximum boost control method offers high stress and traditional space vector modulation gives medium stress in the graph. Figure 10 (d) shows the graph between shoot-through duty ratio Vs boost factor. In case of variable shoot-through duty ratio (maximum boost, traditional SVM and modified SVM), high inductance is required since the inductor current has six times load frequency current ripple. In addition, there are large oscillations in both the capacitor voltage and the inverter input voltage which increases the voltage stress in the power switching. Moreover, the total harmonic distortion (THD) for these three methods is larger than other methods with fixed shoot-through duty ratio. 
Gain Vs Modulation index
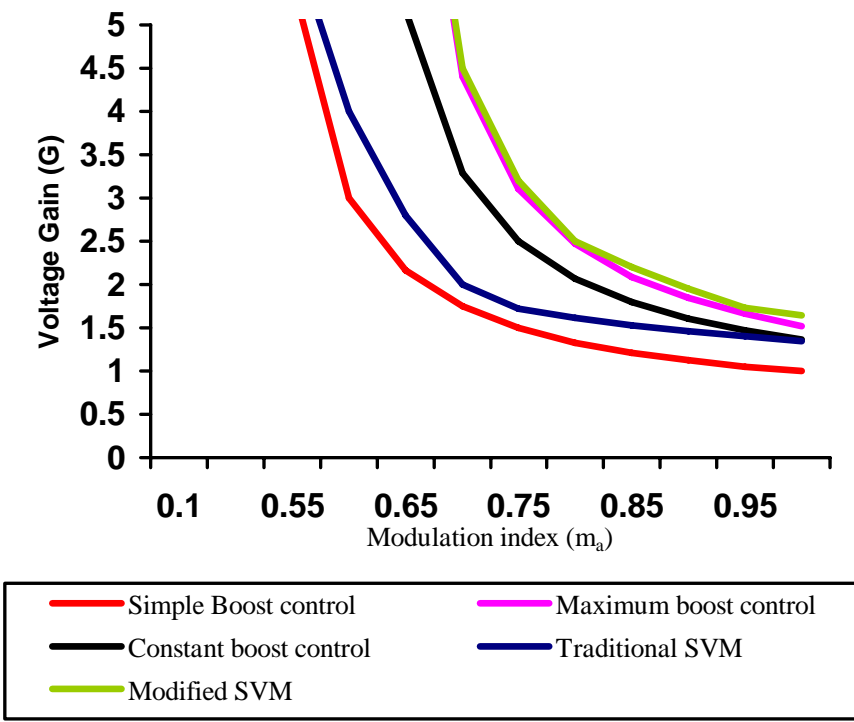

(a)

Voltage stress Vs Modulation index
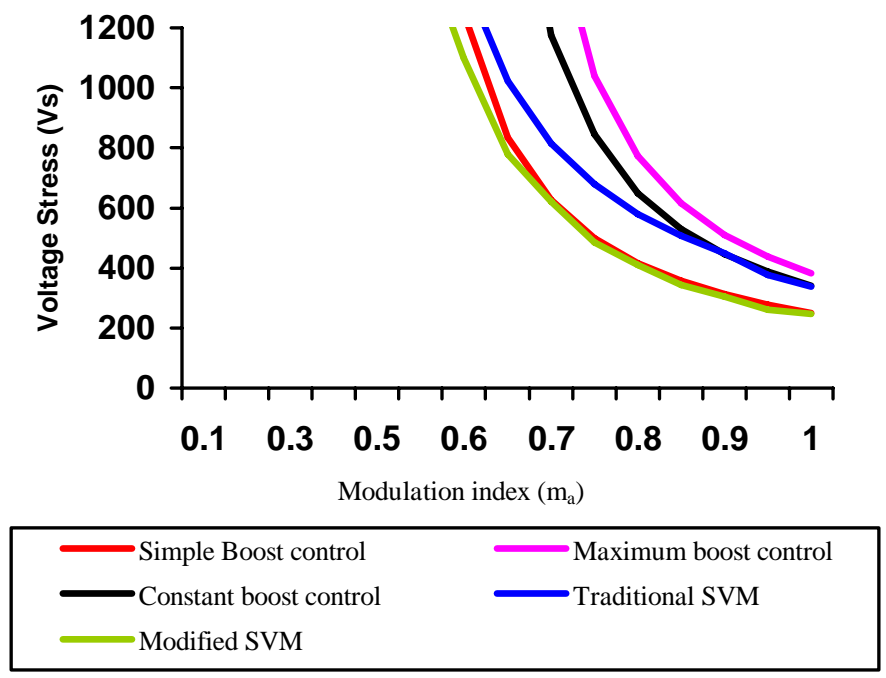

(c)
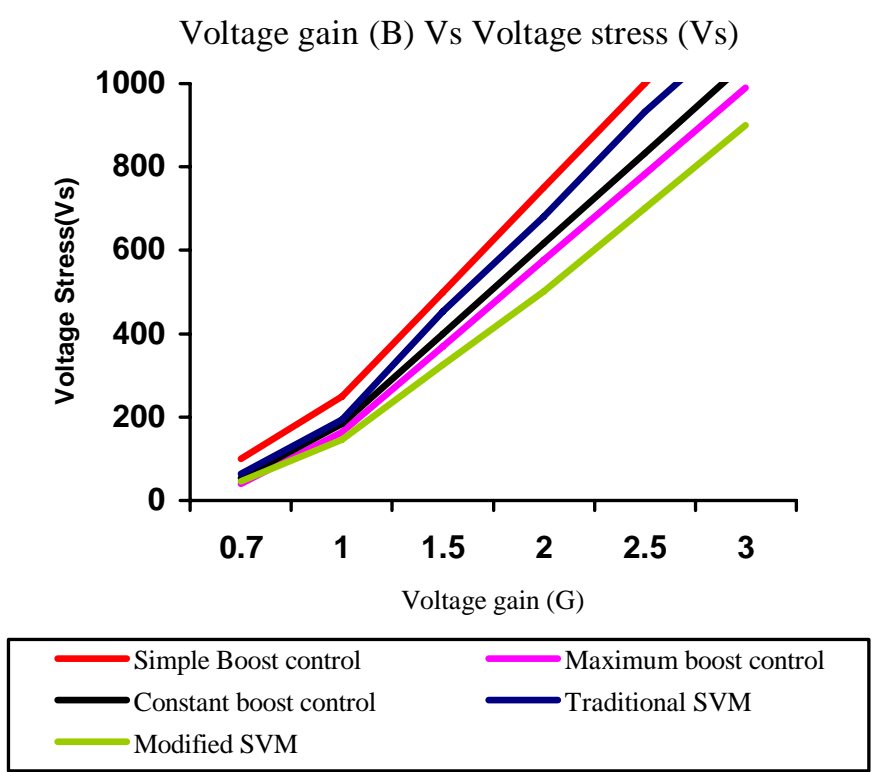

(b)
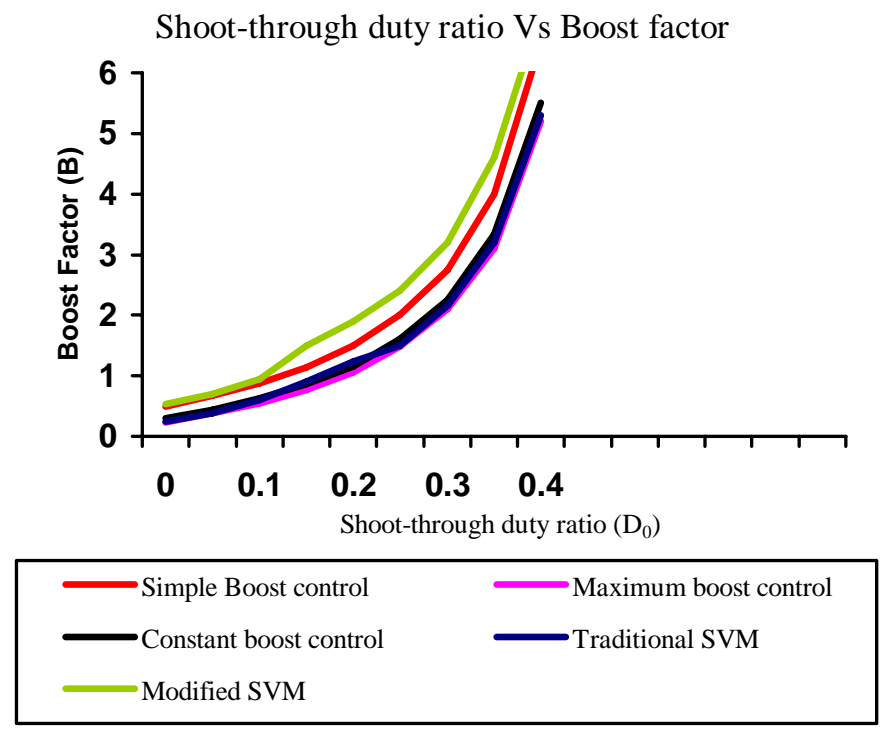

(d)

Figure 10 Comparative graphs of various factors

(a) Voltage gain Vs modulation index

(c) Voltage stress Vs modulation index (b) Voltage gain Vs voltage stress

(d) Boost factor Vs shoot-through duty ratio

In SBC, MBC and CBC methods the shoot-through current is equally distributed on the three phases of the inverter bridge which limit the current stress on the switch. But, in traditional and modified SVM methods, the shoot-through current for each phase is twice the inductor current, which increase the current stress on the switch. Also, in high power range the PWM strategy with six shoot-through state insertions in one switching cycle (traditional SVM and modified SVM) brings more losses than its counterpart of two shoot-through state (SBC, MBC and CBC) insertions in one switching cycle and higher switching frequency makes the efficiency gap become larger. On the other hand, in low output power range, the PWM strategy with six shoot-through state insertions is superior. Maximum boost control method introduces a low frequency current ripple associated with the output frequency in the inductor current and the capacitor voltage. This will cause a higher requirement of the passive components when the output frequency becomes very low. Hence the maximum boost control is suitable for applications that have a fixed or relatively high output frequency. Constant boost control method is very suitable for minimizing the $Z$-source network, especially in low-frequency or variable-speed-drive applications (Peng et al., 2005b). Space vector modulation methods are suitable for variable 
speed drives supplied by fuel cell stack or photovoltaic system (which has fluctuating power supply or voltage sag). In case of bidirectional or high performance Z-source inverter, the deriving signal of S7 (which is connected in series to the dc battery) is complement with the shoot-through signal, which is six times the average switching frequency of the inverter in space vector PWM methods which increase the switching losses of the inverter and lower its efficiency (Ding et al., 2007 and Tang et al., 2009). From the FFT analysis up to $100 \mathrm{kHz}$, the total harmonic distortion of the output current of the constant boost method is lower than all PWM control methods in all topologies.

\section{Conclusions}

In this paper, five major types of pulse width modulation control methods for Z-source inverter have been reviewed and compared. By comparing them, proper control method can be selected according to the requirement of different loads and demands. The simulations have been developed in Matlab/Simulink environment for Z-source inverter with three phase RL load. The comparison results show, the modified space vector modulation provides better operation with effective dc boost and lowest harmonics. Based on the comparative evaluation, the suitability of the control methods for different applications is also outlined. The future work may be extended for the comparison of these pulse width modulation techniques for multi level Z-source inverters with specific operating conditions.

\section{Nomenclature}

$\begin{array}{ll}\mathrm{Z} & \text { Impedance } \\ D_{0} & \text { Shoot-through duty ratio } \\ T_{0} & \text { Shoot-through period in one switching cycle } \\ T_{S} & \text { Switching cycle time period } \\ \mathrm{SBC} & \text { Simple boost control } \\ \mathrm{MBC} & \text { Maximum boost control } \\ \mathrm{CBC} & \text { Constant boost control } \\ \mathrm{SVM} \& \mathrm{MSVM} & \text { Space vector modulation \& Modified space vector modulation } \\ \mathrm{PWM} & \text { Pulse width modulation } \\ \mathrm{THD} & \text { Total harmonic distortion } \\ B & \text { Z-source capacitor voltage boost factor } \\ G & \text { Voltage gain of the inverter } \\ m_{a} & \text { Modulation index } \\ \hat{v}_{a c} & \text { Average output voltage } \\ v_{d c} & \text { Input dc voltage } \\ s p \& s n & \text { Switches connected in positive dc rail and negative dc rail } \\ T_{z} & \text { Traditional zero vector time period } \\ \mathrm{C} 1 \& \text { C2 } & \text { Z-source diagonal capacitors (split capacitors) } \\ \mathrm{L} 1 \& \mathrm{~L} 2 & \text { Z-source inductors (split inductors) } \\ R_{L} \& L & \text { Load resistance \& Load inductance } \\ f_{S} & \text { Switching frequency }\end{array}$

\section{References}

Ding X., Qian Z., Yang S., Cui B. and Peng F. Z., 2007. A new adjustable speed drives (ASD) system based on high- performance Z-source inverter, Proceedings of Industry Applications Conference (IEEE-IAS 2007), pp. 2327-2332.

Loh P. C., Vilathgamuwa M. V., Lai Y. S., Chua G. T. and Li Y. W., 2005. Pulse width modulation of Z-source inverters, IEEE Transactions on Power Electronics, Vol. 20, No. 6, pp. 1346-1355.

Loh P. C., Vilathgamuwa D. M., Gajanayake C. J., Lim Y. R. and Teo C. W., 2007. Transient modeling and analysis of pulse width modulated Z-source inverter, IEEE Transactions on Power Electronics, Vol. 22, No. 2, pp. 498-507.

Peng F. Z., 2003. Z-source inverter, IEEE Transactions on Industrial Applications, Vol. 39, No. 2, pp. 504-510.

Peng F. Z., Shen M. and Qian Z., 2005a. Maximum boost control of the Z-source inverter, IEEE Transactions on Power Electronics, Vol. 20, No. 4, pp. 833-838.

Peng F. Z., Yuvan X., Fang X. and Qian Z., 2005b. Z-source inverter for motor drives, IEEE Transactions on Power Electronics, Vol. 20, No. 4, pp. 857-863.

Shen M. and Peng F. Z., 2008. Operation modes and characteristics of the Z-source inverter with small inductance or low 
power factor, IEEE Transactions on Industrial Electronics, Vol. 55, No. 1, pp. 89-96.

Shen M., Wang J., Joseph A. and Peng F. Z., 2006. Constant boost control of the Z-source inverter to minimize current ripple and voltage stress, IEEE Transactions on Industry Applications, Vol. 42, No. 3, pp. 770-778.

Tang Y., Xie S., Zhang C. and Xu Z., 2009. Improved Z-source inverter with reduced Z-source capacitor voltage stress and soft -start capability, IEEE Transactions on Power Electronics, Vol. 24, No. 2, pp. 409-415.

Thangaprakash S. and Krishnan A., 2010a. Integrated control algorithm for an effective control of Z-source inverter using modified voltage space vector, Australian Journal of Electrical and Electronics Engineering, Vol. 7, No. 1, pp. 1-12.

Thangaprakash S. and Krishnan A., 2010b. Modified space vector modulated Z-source inverter with effective DC boost and lowest switching stress, The Journal of Engineering Research, Vol. 7, No. 1, pp. 70-77.

Tran Q. V., Chun T. W., Ahn J. R. and Lee H. H., 2007. Algorithms for controlling both the DC boost and AC output voltage of Z-source inverter”, IEEE Transactions on Industrial Electronics, Vol. 54, No. 5, pp. 2745-2750.

Woo J. and Keyhani A., 2007. Control of a fuel cell based Z-source converter, IEEE Transactions on Energy Conversion, Vol. 22, No. 2, pp. 467-476.

\section{Biographical notes}

S. Thangaprakash received Bachelor of Engineering in Electrical and Electronics Engineering from Kongu Engineering College and Master of Engineering in Power Electronics and Drives from Government College of Technology, Tamilnadu, India in 2002 and 2004 respectively. He is affiliated with the Department of Electrical and Electronics Engineering, Sri Shakthi Institute of Engineering and Technology, Coimbatore, India. From 2004 to 2008, he was a Lecturer in the Department of Electrical and Electronics Engineering, K.S.R. College of Engineering, Tiruchengode, Tamilnadu, India. Currently he is working towards his PhD degree at Anna University, Chennai, India. His research interests include power electronics circuits, renewable power conversion systems and solid state control of electrical drives. He has authored more than 10 publications in international journals and conferences. He is a life member of ISTE.

A. Krishnan received Bachelor of Engineering in Electrical Engineering and Master of Engineering in Control Systems from Madras University, India in 1966 and 1974, respectively. Then, he received his PhD degree in Electrical Engineering (Control \& Computers group) from the Indian Institute of Technology, Kanpur in 1979. He has been in the field of technical teaching and research for more than four decades at Government College of Technology and Coimbatore Institute of Technology, Tamilnadu, India. From 1994 to 1997, he was an Associate Professor in Electrical Engineering at University Pertanian Malaysia (UPM), Malaysia. Currently he is a Dean with K.S.R. College of Engineering, Tamil Nadu, India. His research interests include control systems, power electronics and electrical machines. He has published more than 180 papers in international journals and conferences. Dr. Krishnan is a senior member of IEEE, Life fellow Institution of Engineers (India), IETE (India) and Computer Society of India.

Received December 2009

Accepted January 2010

Final acceptance in revised form February 2010 